\title{
Dispositivos Normalizadores da Instrução Pública no Brasil e em Sergipe
}

Standardization Devices of Public Education in Brazil and Sergipe

Dispositivos Normalizadores de la Instrucción Pública en Brasil y en Sergipe

\author{
Martha Morais Minatel \\ Universidade Federal de Sergipe (Brasil) \\ https://orcid.org/0000-0003-3475-7434 \\ http://lattes.cnpq.br/3621113172277748 \\ marthaminatel@hotmail.com \\ Verônica dos Reis Mariano Souza \\ Universidade Federal de Sergipe (Brasil) \\ https://orcid.org/0000-0001-8076-098X \\ http://lattes.cnpq.br/4646126026926019 \\ veronicamariano@live.com
}

\section{Resumo}

O objetivo foi discutir a relação entre os saberes biomédicos e a educação, por meio da construção de dispositivos normalizadores da infância na instrução pública. Os objetivos específicos norteadores do trabalho foram: compreender o processo de aproximação dos saberes biomédicos da educação; discutir a influência da Psicologia experimental no pensamento escolanovista no discurso de Lourenço Filho; e apresentar dispositivos disciplinares usados para normalização da educação e da infância no Brasil e em Sergipe nas primeiras décadas do século XX. Pautado na História Cultural e no paradigma indiciário foram usadas fontes bibliográficas e documentais. Em vários estados brasileiros foram identificadas estratégias e dispositivos instituídos para a normalização da infância e da sociedade, com destaque no território sergipano para a instituição do Serviço de Assistência aos Psicopatas e o Gabinete de Biologia Criminal que marcaram a vida de muitos sergipanos quanto às possibilidades de estar ou não na escola e na vida social.

Palavras-chave: História da Educação. História de Sergipe. Escola Nova. 


\begin{abstract}
The objective of this paper was to discuss the relationship between biomedical knowledge and education, through construction of standardization devices of childhood in public education. The specific objectives of this paper were: to understand the process of approaching a biomedical knowledge to education; to discuss the influence of experimental psychology on Escolanovista thought in a discourse by Lourenço Filho; and present disciplinary devices used to normalize education and childhood in Brazil and Sergipe at first decades of 20th century. Based on Cultural History, and on indexing paradigm, bibliographical and documentary sources were used. Strategies and mechanisms established for normalization of childhood and society had been identified in several Brazilian states, with emphasis in Sergipe for establishment of Psychopathic Assistance Service and Office of Criminal Biology that have marked the lives of many Sergipe people with respect to possibilities of being or not in school and in social life.
\end{abstract}

Keywords: History of Education. History of Sergipe. New school.

\title{
Resumen
}

El objetivo de este trabajo fue discutir la relación entre los saberes biomédicos y la educación, por medio de la construcción de dispositivos normalizadores de la niñez en la instrucción pública. Los objetivos específicos que orientaron el trabajo fueron: comprender el proceso de aproximación de los saberes biomédicos de la educación; discutir la influencia de la Psicología experimental en el pensamiento escolanovista en el discurso de Lourenço Filho; y presentar dispositivos disciplinares usados para normalización de la educación y de la niñez en Brasil y en Sergipe en las primeras décadas del siglo XX. Reglado en la Historia Cultural y en el paradigma indiciario usamos fuentes bibliográficas y documentales. En varios estados brasileños se identificaron estrategias y dispositivos instituidos para la normalización de la niñez y de la sociedad, con destaque en el territorio de Sergipe para la institución del Servicio de Asistencia a los Psicópatas y el Gabinete de Biología Criminal que marcaron la vida de muchos sergipanos a lo que se refiere a las posibilidades de estar o no en la escuela y en la vida social.

Palabras-clave: Historia de la Educación. Historia de Sergipe. Escuela Nova. 


\section{Introdução}

Os dispositivos de normalização, ainda que possam ser inconscientes aos indivíduos, servem a determinada época e são produzidos por múltiplos saberes que objetivam os indivíduos. Especificamente na história da infância, essa estratégia de poder foi responsável pela produção de discursos e práticas junto à grupos categorizados como o débil mental, o doente mental, o menor delinquente, o idiota e o imbecil, por exemplo.

No cenário de transformações do século XIX, caracterizado pela racionalidade científica e pelo liberalismo, importava não somente governar o indivíduo, mas seu conjunto a população, constituindo o que Foucault (1984) chamou de biopolítica. Nessa direção, a vida, tomada como parte do campo do poder, tornou-se preocupação política, portanto, por meio de biopoderes caracterizou-se uma "grande medicina social" que estava ligada à manutenção da ordem e da disciplina, visando ao crescimento do Estado, que, por sua vez, passou a se ocupar dos acontecimentos da vida da população como preocupação política, emergindo uma gestão da saúde, da higiene, da alimentação, da natalidade, dentre outros.

Pensar à luz de Foucault sobre a lógica dos biopoderes é uma das formas possíveis de compreender as práticas e preocupações do início do período republicano no Brasil - de construção do homem novo. No momento em que a preocupação ultrapassou o interesse de aprimoramento das habilidades e de sujeição dos indivíduos e atingiu mecanismos que os tornaram mais úteis e obedientes, foi necessário um regime disciplinar (FOUCAULT, 1999) produzindo discursos de verdade, práticas e políticas que ressignificaram os indivíduos, sua cultura, pois atingiu os corpos, os gestos, os comportamentos. Investiu-se nas famílias, escolas, hospitais, sobre todo espaço que permitia a gestão dos indivíduos, controlando sua conduta, intensificando sua performance e utilidade.

Dentro das ramificações do biopoder, os saberes biomédicos caracterizados pela Medicina Social, pelo Higienismo, pela Psiquiatria e pela Psicologia foram campos que produziram dispositivos de normalização da vida da população por meio da produção de um saber que se configurou sob o jugo da regeneração e prevenção de todos os males.

No Brasil, no período republicano, houve práticas médicas higienistas na ordenação da sociedade, das famílias e das escolas. A crescente urbanização, as novas formas de vida e organização familiar, pouca ou nenhuma infraestrutura, a pobreza e uma massa cultural considerada inferior tornaram objeto da medicina: a moral, os costumes, a cultura, as práticas, os corpos, os saberes e fazeres dos indivíduos e sobre isso se intervém com o respaldo da ciência.

A pedagogia moderna foi apoiada por ideias higiênicas na organização das práticas e na formação de saberes a serem ensinados para a reconstrução dos costumes e hábitos de vida saudáveis, sobretudo, no fim do século XIX e nas primeiras décadas do século XX, tendo como propósito a "regeneração social". Nessa direção, os saberes médicos higiênicos e a pedagogia científica constituíram discursos produzidos por determinadas instâncias de poder que unidas produziram a normalidade na infância e, conseguinte, sua anormalidade, ou seja, quem seriam os educandos na escola e quem estaria fora dela.

Nas décadas de 1920 e 1930 ganharam força no Brasil ideais de inovação escolar, implicadas com uma Pedagogia renovada, cientificizada pela Biologia e principalmente pela Psicologia, com pressupostos de eficiência, pragmatismo e utilidade à vida e sociedade que se pretendia construir, portanto, foram ideias que encontraram espaço em uma sociedade republicana desejosa de desenvolvimento. O fortalecimento das práticas inovadoras e do caráter autoritário na determinação das mudanças no cenário educacional aconteceu principalmente com o Golpe de Estado de 1937, momento de destaque para o advento das ciências que trazem elementos científicos para pensar a infância. 
Durante as quatro primeiras décadas do século $\mathrm{XX}$ houve um desencadeamento de práticas, dispositivos e instituições voltadas à normalização da infância no Brasil. O espaço da escola foi reservado à "caçada dos anormais" (LOBO, 2015). Primeiro com as práticas higiênicas e, depois, com a intervenção da Psicologia no bojo da Escola Nova (por meio dos testes e intervenções tanto no campo experimental como psicanalítico, que definiam aqueles que eram educáveis e os que não eram educáveis) dentro da perspectiva da higiene mental que estava difusa em todas as instâncias da sociedade.

Ao mesmo tempo houve um aumento significativo na institucionalização da anormalidade com a fundação das instituições voltadas para esse fim, por meio de ramificações nos manicômios para o cuidado específico à infância como pela construção de instituições especiais de tratamento, educação e proteção, legitimadas pelo discurso produzido em torno dos "não educáveis" pela escola, e pelo projeto de sociedade e homem que se solidificava de uma nação eficiente.

Neste cenário, as práticas normalizadoras da infância por meio da tessitura da relação de poder entre a educação e os saberes biomédicos foram ramificadas para os estados da nação. Assim como em São Paulo, no Rio de Janeiro e demais estados, em Sergipe também foram produzidos dispositivos de captura da anormalidade, de normalização da educação e de governo da infância.

O objetivo deste trabalho foi discutir a relação entre os saberes biomédicos e a educação por meio da construção de dispositivos normalizadores da infância na instrução pública no Brasil e em Sergipe. Para tanto, alguns objetivos específicos foram norteadores: compreender o processo de aproximação dos saberes biomédicos (higienismo, psiquiatria, psicologia) da educação; discutir a influência da psicologia experimental no pensamento escolanovista por meio do discurso produzido por Lourenço Filho; e apresentar alguns dispositivos disciplinares usados para normalização da educação e da infância no Brasil e em Sergipe nas primeiras décadas do século XX.

Este estudo apoiou-se metodologicamente na História Cultural, considerando o paradigma indiciário de Ginzburg $(2006,2011)$ como ferramenta de investigação e análise. O principal teórico para dialogar com as fontes utilizado foi Foucault, além de um diálogo constante com autores do campo da História da Educação e da Educação Especial.

As fontes utilizadas foram bibliográficas e documentais. Entre as fontes bibliográficas, foram utilizadas fontes primárias: a obra de Lourenço Filho (1978) "Introdução ao estudo da escola nova: bases, sistemas e diretrizes da pedagogia contemporânea"; a obra de Fontoura (1965) "Fundamentos de Educação - Uma Introdução Geral à Educação Renovada e À Escola Viva: Princípios Psicológicos e Sociais, Elementos de Didática, Administração Escolar"; e a obra de Arruda (1991) "Os primórdios da psiquiatria em Sergipe"; e fontes secundárias: literatura sobre a História da Educação no Brasil e sobre a história da institucionalização da infância "anormal". Como fontes documentais, foram utilizados documentos provenientes do Serviço de Assistência aos Psicopatas em Sergipe (S.A.P.S.) como ofícios e prontuários de internos dos hospitais psiquiátricos sergipanos (SERGIPE, 2016) ${ }^{1}$.

\section{A Educação e os Saberes Biomédicos}

Para compreender o movimento realizado pelo saber médico junto à educação, faz-se necessário voltar ao início dessa aproximação ainda no século XIX. Dois aspectos se destacaram nessa configuração: a medicina deveria penetrar na sociedade (incorporando o meio urbano como alvo de saber e prática) e deveria apoiar o exercício de poder por parte do Estado (GONDRA, 2010; MACHADO, 1978).

\footnotetext{
${ }^{1}$ Este trabalho foi submetido ao Comitê de Ética e Pesquisa envolvendo Seres Humanos da Universidade Federal de Sergipe e foi aprovado (Número do Parecer: 1.586.277).
} 
Ao penetrar nos mais diversos campos da sociedade, a Medicina Higiênica afirmou o que deveria ser reconhecido como um problema na ciência médica e objeto do seu saber, fabricando discursos e prescrevendo práticas e, a infância, não ficou fora dessa captura. Para Gondra (2002), a infância tornou-se um tema caro à medicina e objeto de um projeto de higienização dos sujeitos e da sociedade. Preocupados desde a união dos pais, até a "idade dos colégios", houve uma demarcação de sua ação entre o privado (a família), e a escola (o público) (GONDRA, 2002, 2015).

Dentro desse projeto higienizador, houve uma ampliação do território de ação da medicina para outras áreas, como a Meteorologia, a Arquitetura, a Geografia e, dentre outras, a Educação. Por meio da educação, as ações médicas puderam chegar ao espaço privado da casa (pela educação dos pais, das famílias ${ }^{2}$ ) e na escola (por meio da normatização do espaço escolar, das práticas desenvolvidas e da formação dos educadores).

Os pais e mestres, considerados como inadequados, segundo Gondra (2010), precisariam ser reinventados pela medicina. $\mathrm{O}$ higienismo e a prática médica serviram como dispositivos normalizadores, na modelação cultural dos grupos, tanto familiar como escolar, modificando as representações e os reinventando na sociedade. A medicina como base para a ordem social, da civilização definiu seu papel pedagógico e fundamentou a ação de todos, sobretudo a organização escolar:

a higiene fornecerá um modelo de organização escolar calcado na razão médica que ao ser constituído retiraria do espaço privado religioso ou familiar- o monopólio sobre a formação dos meninos e das meninas. Para tanto, apela-se aos argumentos científicos que recobrem um amplo espectro de questões vinculadas à escola, tais como o problema da localização dos edifícios escolares, da necessidade de uma edificação própria e apropriada para funcionar como escola, do ingresso dos alunos, do tempo e dos saberes escolares, da alimentação, do sono, do banho, das roupas, dos recreios, da ginástica, das percepções, da inteligência da moral e, inclusive das excreções corporais (GONDRA, 2010, p.527).

De acordo com Gondra (2010), a adesão ao higienismo pelos saberes educacionais desenvolveu a crença de um poder indeterminado na educação, representando uma "nova era", a qual teria o papel de instruir e moralizar, com finalidade de apoiar a ordem e o desenvolvimento da civilização brasileira.

A união entre os saberes médico-pedagógicos tornou-se possível haja vista o cenário de cientificidade moderno que atribuiu à ciência o caráter de progresso e desenvolvimento, assim, a cientificização da Pedagogia como campo das Ciências Humanas, que tem a infância como seu principal objeto, foi alimentada e fortalecida pela relação com outros discursos de verdade, como o Higiniesmo e a Psicologia, por exemplo.

Por essa relação de poder dos saberes pedagógicos e biomédicos foi possível constituir um aparelho específico de governo da infância na medida que funcionava segundo normas e normalizações, testes e exames que enquadravam as ações da criança "[...] produzindo um sujeito/objeto-aluno, transformando a criança em aluno, cuja conduta deve se pautar pelas regras desse governo pedagógico" (RESENDE, 2015, p.134).

Foram as técnicas disciplinares de exame, de hierarquia, de vigilância e sanções que visavam à normalização da infância que transformaram a escola em um laboratório de

\footnotetext{
${ }^{2}$ Para maior esclarecimento do processo de desqualificação das famílias pelos saberes higienistas, conferir Cunha (2010), o autor apresenta uma análise histórica do jogo de poderes entre família e escola (respaldada pelo discurso médico e psicológico) como o dispositivo responsável (e talvez único, por sua cientificidade) pela educação da infância.
} 
constante individualização e investigação, na qual a criança assujeitada foi objetivada. Desse jogo, houve um produto, uma representação da criança normal e anormal, da infância que se almejava para a nação.

Essas práticas na captura e identificação da anormalidade no contexto educacional ganharam destaque com as reformas educacionais para implantação de um ensino embasado pelo movimento escolanovista nas primeiras décadas do século XX.

Segundo Lourenço Filho (1978) a expressão escola nova refere-se a um novo tratamento dos problemas da educação:

Não se refere a um só tipo de escola, ou sistema didático determinado, mas a todo um conjunto de princípios tendentes a rever as formas tradicionais do ensino. Inicialmente, esses princípios derivaram de uma nova compreensão de necessidades da infância, inspirada em conclusões de estudos da biologia e da psicologia. Mas alargaram-se depois, relacionando-se com outros muito numerosos, relativos às funções da escola em face de novas exigências, derivadas de mudanças da vida social (LOURENÇO FILHO, 1978, p.17).

Para Lourenço Filho (1978), o movimento questionou a normalização ${ }^{3}$ do ensino, primando pela individualização e conhecimento da natureza de cada ser; apoiado, sobretudo, na Biologia (com contribuições sobre antropometria, maturação, bem como de outras disciplinas como a Puericultura, higiene e Medicina dentre outras) e na Psicologia experimental.

Para compreender o uso dos saberes psicológicos na educação pelos escolanovistas, a seguir, pautado na obra de Lourenço Filho "Introdução ao estudo da escola nova..."4, pretendeu-se analisar essa relação destacando os saberes e dispositivos apropriados pelo professor na construção do seu discurso.

\section{Contribuições da Psicologia no Pensamento de Lourenço Filho: Psicometria, Personalidade e Desvios da Normalidade}

Lourenço Filho (1978) apresentou três grandes contribuições da psicologia à renovação escolar: 1) a descrição das variações psicológicas através das idades; 2) a caracterização objetiva das semelhanças humanas e individuais; 3) a criação de um modelo explicativo genético-funcional.

No primeiro ponto, o autor comparou a evolução psicológica da criança ao desenvolvimento físico, devendo essa também seguir um padrão. Similar à antropometria desenvolveu-se a psicometria, pautada principalmente no conhecimento desenvolvido por Alfred Binet e seus colaboradores na França, tendo como objetivo, relacionar a evolução psíquica ao desenvolvimento da inteligência e ao desempenho escolar.

Quanto ao segundo ponto, Lourenço Filho exaltou a compreensão das variações psicológicas através das idades como ferramenta para traçar uma normalização das crianças, ou seja, padrões de comportamentos típicos ou representativos em cada idade, possibilitando a criação de grupos homogêneos. Contudo, faz uma ressalva que grupos homogêneos não devem ser sinônimo de uma padronização entre os alunos, pois são semelhantes somente por

\footnotetext{
${ }^{3} \mathrm{O}$ termo normalização, questionado por Lourenço Filho nas escolas tradicionais, parece estar ligado à ideia de padronização, o que se diferencia das críticas e análises posteriores que outros autores realizam sobre o movimento escolanovista de prover uma normalização da educação por meio da individualização dos alunos, pois ao passo que os enquadra, classifica e separa produz-se uma normalização educacional, excluindo para outras instituições os educandos que não respondiam aos mesmos critérios.

${ }^{4}$ A edição analisada neste trabalho foi publicada em 1978, sendo a primeira publicada em 1929.
} 
expressões gerais, não quanto às particularidades ou características, pois todos diferem entre si, o que legitima e amplia o uso dos testes mentais, de personalidade e comportamento para a individualização das crianças:

Hoje, o mestre sabe que está em face de educandos similares em grupos, mas todos diferentes entre si, e que, em consequência, terá de adaptar o ensino não só em relação às fases evolutivas, mas também às diferenças de cada aluno em particular. Mediante provas relativamente simples é possível obter um diagnóstico do educando. É possível também prognosticar, ou ter ideia do que se deva esperar de cada criança ou jovem, com a adoção nos casos necessários de procedimentos educativos especiais, indicados pelos resultados de provas de rendimento e de personalidade (LOURENÇO FILHO, 1978, p. 73-74, grifado no original).

O trecho transcrito acima ilustra a apropriação pela educação das terminologias médicas (como diagnóstico e prognóstico) e da importância da individualização dos sujeitos por meio de testes específicos revelando as relações de poder fundamentadas pelos discursos de verdade produzidos nas instâncias educacionais, médicas e da psicologia no assujeitamento da infância e na objetivação de sua normalidade. Enquanto práticas discursivas que produziram representações e apropriações pelos sujeitos foi possível a produção e identificação dos desvios na infância que poderiam ser "salvos" por meio da educação, disciplina pela qual todos deveriam passar (ainda que apenas para sua classificação e exclusão devido a seu "prognóstico").

Lourenço Filho (1978) enalteceu os trabalhos desenvolvidos em Paris por Alfred Binet e Théodore Simon para identificar "os menos dotados" por meio de testes estatísticos para a caracterização das crianças. Além das escalas psicométricas produzidas por esses autores, outro instrumento, o índice do Quociente de inteligência também é apresentado pelo professor:

Um novo conceito foi também elaborado, para comparação do nível obtido por crianças e adolescentes com os níveis normais das idades sucessivas. Para esse efeito, usa-se de um índice muito simples chamado quociente de inteligência, ou abreviadamente Q.I., ideado por Wilhelm Stern (1871-1938). Para isso, bastará dividir a idade mental, tal como obtida nos testes, pela idade cronológica, multiplicando-se o resultado por 100. Desse modo, também operacionalmente vem-se a dar precisao a certos adjetivos, como normal, avançado, retardado, limítrofe, débil talentoso, genial. (LOURENÇO FILHO, 1978, p.73, grifado no original)

Outros testes para o diagnóstico das capacidades específicas, aptidões, níveis de comportamento motor, níveis de maturidade com relação a atividades específicas, níveis de adaptação emocional e social, etc. também foram citados por Lourenço Filho, bem como o uso de técnicas mais complexas, que caberiam à psicologia clínica, por meio de um estudo aprofundado do aluno: às provas de rendimento, deveria ser somada a observação dinâmica do comportamento com provas da personalidade. Tal técnica seria importante nos casos de "crianças problema", por exemplo.

Em relação à contribuição da psicologia em oferecer um modelo explicativo genéticofuncional, Lourenço Filho destaca a importância da hereditariedade (caráter genético) e da 
interação organismo-ambiente (funcional) na caracterização e determinação do comportamento humano.

Além das contribuições gerais, apresentadas acima, Lourenço Filho escreveu sobre "os grandes constructos" da psicologia, considerando-os determinantes no processo educacional. São eles: motivação, aprendizagem e personalidade. Segundo o professor, a motivação e a aprendizagem levam ao ajustamento individual, um estado de equilíbrio entre o indivíduo e o ambiente. Contudo, ainda que se conhecesse o nível de motivação e aprendizagem da criança, somente a compreensão da personalidade do educando forneceria dados sobre o que ele teria capacidade de fazer. Portanto, a personalidade ganha lugar de destaque, sendo definida como a "qualidade da pessoa".

A descrição da personalidade deveria ser feita pela enumeração de atributos de uma pessoa. A observação subjetiva, deveria dar lugar a dados operacionais, mediante provas de rendimento, escalas, questionários ou testes especiais de personalidade, dando ênfase ao caráter quantitativo em detrimento do qualitativo.

A partir dessa descrição quantitativa da personalidade, Lourenço Filho alerta que, os educadores, deveriam estar atentos à sua estruturação funcional proveniente da interação dos componentes gerais como constituição física, temperamento, inteligência, aptidões e a cultura adquirida, pois essa interação configurava a personalidade, admitindo assim, uma organização dinâmica, não estática, portanto, local de intervenção do professor: " [...] o objetivo central da educação é formar personalidades, desenvolvê-las e aperfeiçoá-las." (LOURENÇO FILHO, 1978, p. 106).

Considerando que a constituição da personalidade inicia-se na família e se desenvolve na interação com os grupos e instituições escolares, Lourenço Filho reforçou o papel dos adultos e do meio nessa construção. Afirma que não há consenso na literatura, sendo que para alguns autores ela se define aos dois anos, para outros aos cinco anos e para outros até a adolescência, sendo essa fase em especial, inundada por razões que levam a perturbação emocional, influindo o modo de ser dessa pessoa; o que leva o professor a concluir que uma boa avaliação da personalidade deve ser longitudinal. Ou seja, nunca deve ser definitiva, mas constante durante o período educacional.

Conceitos desenvolvidos nas teorias sobre o desenvolvimento da personalidade são evocados para justificar comportamentos no campo educacional, bem como os "desajustes" dos alunos diante do que lhes era esperado, como por exemplo, os mecanismos de defesa. Embasado por teorias que falam do adulto "normal", Lourenço Filho, diz que os mecanismos de defesa podem ser agrupados de acordo com os efeitos sociais que produzem, são eles: mecanismos socialmente convenientes (compensação, racionalização e substituição); socialmente tolerados (identificação, projeção e egocentrismo); socialmente criticáveis (regressão e dissociação); e socialmente reprovados (repressão, negativismo e autismo).

Esse ajustamento do indivíduo diante da realidade revela a compreensão do autor quanto ao ajustamento normal e anormal. Para ele o limite da normalidade dos mecanismos é tênue, podendo caracterizar reações patológicas desencadeadoras de doenças mentais. Quanto a esse grupo de indivíduos afirma a difícil tarefa de classificá-los, preferindo os especialistas dividir as doenças mentais em neuroses e psicoses.

Os neuróticos encontram de modo geral dificuldades de ajustamento sem que, por isso, tenham de ser retirados do convívio social. Manifestam inquietação, temores infundados, vacilações e impressão de fadiga constante, mantendo, porém, suas capacidades de inteligência e orientação no ambiente, não são assim diferentes das pessoas normais quanto aos aspectos gerais do comportamento, embora sofram, e por isso, reclamem tratamento. Nas psicoses o quadro é mais grave. $\mathrm{O}$ 
paciente perde o contato com o mundo ambiente, donde o nome de alienado, isto é alheado do mundo. Seu comportamento torna-se perigoso para si e os outros, havendo necessidade de sua internação em hospitais apropriados. Há psicoses cujas causas são claramente atribuídas à deterioração do sistema nervoso, recebendo por isso o qualitativo de orgânicas. Outras há em que isso não ocorre, donde o nome de psicoses funcionais. Acredita-se que estas provenham de dificuldades de ajustamento, adquiridas sobretudo no período da infância." (LOURENÇO FILHO, 1978, p.113, grifado no original)

A abordagem das doenças mentais em um livro destinado à educadores, traz questionamentos importantes quanto ao uso desse saber. A diferenciação dos quadros patológicos (da doença mental) justifica a sua retirada do meio educacional e internação nos hospitais apropriados retirando qualquer responsabilidade da escola em prover adequações para o acolhimento desses sujeitos. É um saber poder médico que sobressai em detrimento de propostas pedagógicas ao ensino dessa população. Ao professor, fica a difícil tarefa de evitar essas doenças, por meio da educação que irá "modelar" a personalidade.

Nessa direção, Lourenço Filho defendeu a ideia de que, além das condições da estrutura hereditária, as atividades da vida social influem sobremaneira as expressões dominantes da personalidade, e, conseguinte, os modos normais e anormais de ajustamento. Entendendo que as neuroses e psicoses são desvios da normalidade predispostas hereditariamente sem descartar a influência do meio ambiente e social diante de situações de conflito e frustração, os níveis de resistência ou tolerância diante destas situações seriam preditores da personalidade, sendo uma das funções da educação criar condições para que cada pessoa por si mesma pudesse elevar tais níveis.

Ainda que considere o caráter coletivo, cultural na constituição do indivíduo e da sua personalidade, Lourenço Filho afirma que as diferenças biológicas se sobressaem: “[...] quaisquer que sejam as condições do ambiente, o oligofrênico, ou débil mental, não poderá exprimir-se como uma pessoa biologicamente bem dotada." (LOURENÇO FILHO, 1978, p. 114). Diante disso, o "poder" do professor em moldar os alunos é limitado por variáveis biológicas, justificadas como "falhas" da criança.

Observa-se a apropriação de um discurso de verdade produzido nos moldes científicos da psicologia experimental no contexto nacional por Lourenço Filho. Entusiasta do trabalho de Alfred Binet e seus colaboradores, tais teorias são apropriadas para a renovação da educação brasileira sem filtros sociais ou culturais. Ferreira (2016) destaca essa ideia ao revelar que os trabalhos de Binet não tiveram o mesmo alcance e aceite em Paris como tiveram no Brasil, considerando que suas proposições iam ao encontro do desejo científico de alguns intelectuais brasileiros, respeitando um caráter elitizado e evolucionista que se escondia por trás de seus princípios.

A proposta defendida por Lourenço Filho deixa clara a importância dada ao caráter quantificável cientificamente da individualidade do seu educando. Sendo a personalidade uma variável manipulável e moldável por meio da educação, a atribuição de uma avaliação longitudinal retoma a perspectiva de risco inerente à infância apresentada por Foucault (2001, 2006). A apropriação das teorias psicológicas pela educação construiria representações sobre o desenvolvimento regular e irregular e forneceria elementos para os professores "arrumarem" os problemas comportamentais advindos do contexto escolar, e assim, diminuiria o fracasso escolar, ao passo que classificando, separando, homogeneizando, seria possível retirar aqueles que, cientificamente, sabe-se que não teriam aproveitamento neste espaço- os casos graves de doenças mentais e idiotas por exemplo. 
Em consonância, na obra de Binet, exclui-se do ensino especial os considerados imbecis e idiotas. Para ele, idiotas seriam aqueles que não conseguem se comunicar pela palavra, mesmo não apresentando problemas nos órgãos relacionados com a fala e a audição a ele restaria o hospício. Os imbecis seriam aqueles que sem apresentar qualquer problema orgânico, não consegue se comunicar através da escrita - restaria os ateliês. Somente os casos leves deveriam ser educados na escola, nas salas especiais (FERREIRA, 2016).

Segundo Ferreira (2016), as teorias de Binet que fundamentavam a "pedagogia individual" partiam de princípios eugenistas, que foram colocados em prática por medidas higienistas adotadas na instrução pública. Medidas disciplinares, de constante avaliação e vigilância transformaram os alunos em "suspeitos" de irregularidades do desenvolvimento.

Não obstante, a abordagem de Lourenço Filho dos desvios da normalidade - como as psicoses e neuroses coadunam com a preposição de Binet apresentada por Ferreira (2016) de que os "atrasados de inteligência" classificados por seus métodos deveriam ser incluídos no estudo da Patologia Mental. Talvez isso explique a apresentação desse conteúdo em um livro destinado a professores.

Do anormal que nunca chegou à escola, e dela, continuou afastado por meio de explicações científicas ainda na primeira metade do século $\mathrm{XX}$, a escola por meio de dispositivos disciplinares, da apropriação de um saber poder sobre a vida, construiu representações do que é normal ou anormal dentro deste espaço, do que deve ser destinado ao ensino especial, a outras instituições de assistência ou para a classe especial ${ }^{5}$.

A seguir, por meio de uma contextualização do processo de implementação das ideias escolanovistas no Brasil e em Sergipe, buscou-se apresentar o que a história tem revelado sobre essas práticas e discursos de normalização da infância.

\section{A Escola Nova e Dispositivos de Normalização da Infância no Brasil e em Sergipe}

Urbanização e industrialização crescentes, processos imigratórios e migratórios, o choque cultural entre a elite letrada e os pobres que chegavam em busca de oportunidades de trabalho são importantes características do cenário brasileiro na década de 1920, impulsionando as campanhas cívicas e a perspectiva de que por meio da educação de todos, um novo homem e uma nova sociedade seriam construídos, a ideia era modernizar a sociedade por meio da escola (CARVALHO, 2010; CUNHA, 2010; NUNES, 2010). Segundo Carvalho (2010), é devido à perspectiva de "regeneração social" por meio da educação que foi instituído, em 1924 no Rio de Janeiro, a Associação Brasileira de Educação.

Desde as reformas da instrução pública desenvolvidas por Lourenço Filho, em 1922 no estado do Ceará, e, posteriormente, em 1926, por Anísio Teixeira no estado da Bahia, iniciou-se uma aproximação com ideias produzidas fora do país que dessem respaldo às inovações pensadas pelos reformistas. A literatura que respaldava o movimento escolanovista brasileiro buscou na discussão internacional sua fundamentação: em Lister, Freeman, Dotrens, Dewey, Ferrière e Decroly (VIDAL, 2010).

Segundo Vidal, as inovações da Escola Nova traziam apropriações dos modelos tradicionais negados, por meio da ressignificação de seus materiais e métodos, como a

centralidade da criança nas relações de aprendizagem, o respeito às normas higiênicas na disciplinarização do corpo do aluno e de seus gestos, a cientificidade da escolarização de saberes e fazeres sociais e

\footnotetext{
${ }^{5}$ Especificamente sobre a influência da obra de Lourenço Filho e dos testes de inteligência provenientes da obra de Binet no contexto sergipano, ver Minatel (2018). A autora aborda o uso desses saberes no estado de Sergipe na constituição das escolas especiais na década 1970.
} 
a exaltação do ato de observar, de intuir na construção do conhecimento do aluno. (VIDAL, 2010, p. 497).

As bases científicas da proposta que emergia como inovação à educação brasileira tinham seus alicerces principalmente nos saberes da Psicologia experimental, fornecendo elementos para a compreensão científica do humano em sua dimensão individual (CUNHA, 2010; LOURENÇO FILHO, 1978; NUNES, 2010; VIDAL, 2010).

Tanto a Revolução de 1930, como o golpe de Estado de 1937, instituindo o Estado Novo por Getúlio Vargas, trouxeram diferentes apropriações das propostas reformistas dos pioneiros da Escola Nova. Segundo Carvalho (2002), no Governo Provisório, foram incorporados tópicos centrais do programa escolanovista para as ações educacionais; como estratégia de configuração e controle técnico e ideológico foi criado o Ministério da Educação e Saúde. Já no Estado Novo, a retórica advinda da Escola Nova foi adotada pelos governistas "homem novo para o Estado Novo".

No estado de Sergipe, um dos expoentes da modernização do ensino foi Helvécio de Andrade, três vezes como Diretor da Instrução Pública: a primeira, no período de 1913 a 1918; a segunda de 1926 a 1927; e a terceira, de 1930 a 1935 (NASCIMENTO, 2003; VALENÇA, 2006). Em sua terceira gestão, Helvécio, preocupado com as mudanças administrativas e pedagógicas que vinham se desencadeando no cenário nacional, enviou o Prof. José Augusto Rocha Lima para São Paulo com o objetivo de estudar os novos métodos (FREITAS, 2011; SILVA, 2002).

No relatório apresentado por Rocha Lima, descrevendo sua visita, ele destaca os materiais de Froebel, Montessori e Decroly nas atividades da pré-escola. Contudo, o professor não se iludiu pelo entusiasmo das novas práticas, propondo adequações à cultura regional sergipana dos métodos visualizados em São Paulo e recomendou que tão pouco fosse feito sem planejamento (SILVA, 2002).

Rocha Lima ficou como assistente técnico geral da Diretoria de Instrução Pública desde sua volta de São Paulo em 1931 até 1942, sendo uma figura importante na difusão do ideário escolanovista (sobretudo das ideias de Decroly) na instrução pública sergipana (SILVA, 2002).

Freitas (2011) apresenta, além de Helvécio de Andrade e José Augusto da Rocha Lima, outros nomes como representantes da implantação das propostas escolanovistas no terreno sergipano: Acrísio Cruz e José Antônio Nunes Mendonça. Segundo a autora, a apropriação do movimento escolanovista em Sergipe foi adequado às necessidades e possibilidades locais, diante do entusiasmo dos intelectuais sergipanos e das resistências enfrentadas. O papel da Associação Sergipana de Educação (fundada em 1934 e apoiada pela Associação Brasileira de Educação) e a estratégia da inspeção escolar junto às reuniões pedagógicas foram importantes difusores dos princípios da Pedagogia da Escola Nova e para a modernização dos métodos pedagógicos no estado (FREITAS, 2011).

Vale destacar que, segundo Nascimento (2003), as reformas em Sergipe não beneficiaram todo o estado, limitando-se a Aracaju, e outros centros urbanos - Capela, Estância, Lagarto e São Cristóvão.

No cenário de efervescência da Escola Nova e da busca pela cientificidade educacional, sobretudo na íntima ligação entre saúde e educação, vários dispositivos de controle e governo da infância e de identificação de sua anormalidade foram instituídos no contexto nacional e também em Sergipe.

Antes mesmo da década de 1920, a tarefa de classificação e busca pelos anormais era ascendente, tendo como um grande marco a instalação do Laboratório de Pedagogia Experimental no Gabinete de Psicologia e Antropologia Pedagógica, anexo à escola Normal Secundária em São Paulo, no ano de 1914. Segundo Carvalho (2006), o objetivo do laboratório era realizar o estudo científico da infância; para isso, o diretor da Escola Normal, 
Oscar Thompson, trouxe o italiano Ugo Pizzoli para ofertar cursos e efetivar a função do Laboratório a qual consistia em aparelhar a Escola Normal com instrumentos de medição e indagação na formulação de um conhecimento científico do indivíduo.

Para Carvalho (2006), o Laboratório de Pedagogia Experimental era um dispositivo de saber e poder que repartia os homens em classes de seres que a natureza tornava desiguais (explicações científicas de antropometria, dados anamnéticos, de antecedentes, hereditariedade, dentre outras questões abordadas no esquadrinhamento da infância).

Com a aproximação da Psicologia das ferramentas de classificação, a Pedagogia científica passou a ter por função: discriminar as crianças normais das anormais ou degeneradas, importando separar os casos de anomalia simples dos graves, pois os primeiros poderiam ser corrigidos e modificados por métodos especiais, já os degenerados deveriam ser excluídos absolutamente das escolas dos normais, segundo o discurso produzido por Thompson (CARVALHO, 2006; FERREIRA, 2016).

Segundo Ferreira (2016), os discursos e práticas desenvolvidas por Thompson tiveram influência das teorias de Binet, tanto nessa compreensão de exclusão dos degenerados como a insistência no "adestramento" dos professores para usar testes e medidas para realizar uma observação cuidadosa e científica de seus alunos. Com o movimento da Escola Nova, o uso dos testes psicológicos foi incorporado às reformas de ensino (CARVALHO, 2006; LOBO, 2015; VEIGA, 2004).

A partir das primeiras décadas do século XX, a inspeção médica instituída nas escolas foi um dispositivo disciplinar que ganhou poder na seleção de alunos e na profilaxia das contaminações de doenças físicas ou mentais.

Segundo Lobo (2015), o movimento escolanovista foi assumido pelos educadores da Associação Brasileira de Educação, em aliança com a Liga Brasileira de Higiene Mental (LBHM), fundada em 1927 por Reidel, na organização das redes de ensino primário no Brasil, introduzindo o instrumental da Psicologia nas escolas e nos cursos normais. A autora faz a leitura desta estratégia de racionalização do sistema como uma "caçada aos anormais" citando uma circular encaminhada em 1927 pela LBHM às professoras de escolas maternais e jardins de infância, para que fizessem o reconhecimento precoce dos anormais.

$\mathrm{Na}$ mesma direção, observou-se no trabalho de Lourenço Filho (1978) os testes psicológicos indicadores de inteligência contribuindo para a organização racional das classes homogêneas, classificando as crianças em anormais, normais e supranormais, formando-se um discurso sobre os anormais enquadrados cientificamente, além de estabelecer categorias pelos testes de inteligência.

Veiga (2004), além de apresentar as classificações presentes no trabalho de Lourenço Filho, apresenta a classificações defendidas por Binet ${ }^{6}$ quanto aos anormais: "[...] idiotas, imbecis e débeis mentais, e o imbecil" (p.77). Ademais, traz que os autores consideram também as condições de saúde física e emocional da criança, produzindo-se outras categorias: “[...] equilibrada, desequilibrada, imatura, madura, portadora de deficiências sensoriais e motoras, e ainda a codificação do grau de ajustamento social: tímida, assustada, medrosa, irritada" (p.77). Finalizando com a denominação "criança problema", que, para Lourenço Filho, são aquelas com dificuldades de ajustamento no meio familiar e na escola, conseguinte na sociedade.

Segundo Lopes (2002), o conceito de "criança problema" foi criado pelo médico e psicanalista Arthur Ramos. Sua contribuição à Pedagogia, segundo a autora, está nessa nova classificação, pois ao olhar para os anormais, ele redefine essa classificação para além dos testes psicotécnicos, aos quais criticava por seu determinismo e simplicidade:

\footnotetext{
${ }^{6}$ Jannuzzi (2006) e Ferreira (2016) destacam a influência de Binet para a quantificação da anormalidade ele comparou a deficiência ao estado normal e estabeleceu uma variação quantitativa, cujo parâmetro foi a escola, gerando o conceito de debilidade mental que chega ao Brasil como aquele que apresenta atraso de dois ou três anos de seu curso de estudo, sem considerar questões sociais, entre outras variáveis.
} 
a revisão de casos de crianças registradas nas escolas como anormais tirou $90 \%$ de crianças dessa condição e sobretudo do tratamento a elas imposto. As crianças com desempenho escolar insatisfatório, inquietas, mentirosas, seriam "crianças problemas" e a atenção que requeriam era outra, muito diferente daquela que obtinham (ou não obtinham) quando portavam o título de anormais. (LOPES, 2002, p.334)

Em 1933 foi fundada a Seção de Ortofrenia e Higiene Mental do Instituto de Pesquisas Educacionais, fruto da reforma produzida por Anísio Teixeira, tendo como diretor Arthur Ramos. Embora próximo de Anísio, discordava dele na organização das salas homogêneas por meio dos testes, portanto, desenvolvia um trabalho complementar a esse, focado na criança e sua família, reflexo de sua preocupação com a higiene mental. A partir de 1934 foram sendo fundadas "clínicas ortofrênicas" nas escolas experimentais e, em 1936, uma primeira "clínica de hábitos" destinada aos pré-escolares (LOPES, 2002).

As clínicas ortofrênicas nas escolas, partem da compreensão de infância de Arthur Ramos como a "idade de ouro para a higiene mental". Nestas clínicas, trabalhariam juntos: o professor, o médico-clínico, o psicopedagogo e o psiquiatra, cujo objetivo era manter normal a criança normal (prevenção) e se houvessem problemas graves, seriam analisados por essa equipe (LOPES, 2002).

A "criança-problema" esteve presente nos livros publicados aos professores sobre o novo prisma educacional. Foi o caso da obra do professor Afro do Amaral Fontoura (1965) no Rio de Janeiro - além de exaltar as contribuições da psicologia quanto à caracterização das diferenças individuais e os princípios classificatórios do nível mental (Q.I.; escalas psicométricas), o professor dedicou um capítulo para abordar a criança-problema e a importância da disciplina escolar.

Definida como "aquela que, por qualquer razão, se desajusta dos padrões da escola ou da norma de conduta infantil, de maneira a constituir um problema para seus pais ou educadores" (FONTOURA, 1965, p.105), a criança problema não seria a criança anormal, seria aquela criança que foge dos padrões sociais usuais sem ter uma anomalia física, intelectual ou moral.

Para essas crianças "anormais", segundo Fontoura (1965), deveriam existir instituições apropriadas, estabelecimentos pedagógicos para internação e para os mais graves, os hospitais neuropsiquiátricos infantis.

Passível de ser corrigida pela educação, Fontoura (1965) defendeu que a criançaproblema era apenas uma "criança desajustada", cujo "desajuste" era fruto da saúde física (e alimentação), da saúde mental, da vida emocional, da vida familiar, da vida econômica, da vida social (meio frequentado pela criança). Ainda, caracterizou os possíveis comportamentos observáveis nesse grupo: rebeldia, capricho, desconfiança, falta de interesse pelos estudos, medo, antipatia contra a escola, ou contra os professores ou colegas, cólera, rixas frequentes, indolência, fugas, turbulência, mentira, incapacidade para aprender, instabilidade da atenção, furto, histeria, enurese (incapacidade de conter as urinas), desordens sexuais, angustia, etc. E a terapêutica deveria ser em cima da pesquisa das causas do desajuste, referenciando Arthur Ramos na relevância da compreensão de cada caso de modo específico.

Outro dispositivo normalizador foi a criação, em 1937, do Laboratório de Biologia Infantil no Rio de Janeiro (CORRÊA, 2006; LOBO, 2015), sendo que como justificativa de sua necessidade e excelência, orgulhavam-se em dizer que nenhum menino por eles avaliados por meio de exames médicos e psicológicos, "era são" (LOBO, 2015, p.369). Esse dado destaca a força da captura da infância em sua anormalidade, tão frágil em sua definição e causas, tudo poderia ser enquadrado, e assim o era, destacando a dimensão do saber poder enquanto discurso de verdade produzido pela dupla medicina-pedagogia no controle social. 
O Laboratório tinha por finalidade estudar os menores abandonados e delinquentes, na busca de encontrar causas físicas e psíquicas para a condição dessas crianças, especialmente em relação à criminalidade (CORRÊA, 2006).

A estreita relação entre as instâncias médicas, jurídicas e educacionais na determinação e destino dos anormais estava presente no discurso e nas práticas dos gestores da nação. Em 1937, Getúlio Vargas prescreveu que no ensino dos "anormais de inteligência", a ação do poder público estaria ligada ao Instituto Nacional de Pedagogia, em conexão com o Serviço de Assistência aos Psicopatas e os "inadaptados morais" ficariam a cargo da Justiça (JANNUZZI, 2006).

Há um paradoxo quanto à assistência ofertada aos "anormais de inteligência", pois ainda que devessem estar atrelados ao Instituto Nacional de Pedagogia, assessorados pelo Serviço de Assistência aos Psicopatas, a história revela que aos anormais de inteligênciaidiotas, imbecis, oligofrênicos - foi destinada somente a assistência do hospital psiquiátrico (JANNUZZI, 2006; LOBO, 2015; VIANA, 2014).

Nos registros dos hospitais psiquiátricos em Sergipe, durante as décadas de 1940 a 1970 (Hospital Colônia Eronides de Carvalho, Hospital Clínica Adauto Botelho e Hospital Garcia Moreno), foram identificados um total de 7.522 prontuários de internações, 184 internações de pessoas consideradas oligofrênicas idiotas, oligofrênicas imbecis ou debilidade mental sem outras comorbidades, sendo que destes, 62 tinham até 18 anos - o caráter educativo em seu tratamento não existia, mas sim, eletrochoque, medicamentoso e reclusão (SERGIPE, 2016).

No estudo realizado por Viana (2014) sobre os diagnósticos de crianças e jovens internados no período de 1942-1944 no Hospital Colônia Sant'Ana em Santa Catarina, a autora problematiza as internações dos oligofrênicos no hospital psiquiátrico, uma vez que para estes era preconizado na literatura científica os tratamentos educacionais.

A autora conclui dizendo que a literatura usada, desde 1914, postulava o tratamento dos oligofrênicos idiotas e imbecis por meio da educação física e moral em estabelecimentos especiais para esse fim, contudo a instituição de seu estudo, o hospital psiquiátrico, não voltava-se para essa função o que revela o quanto o processo histórico de valorização do trabalho e da educação não permitiram que os anormais se enquadrassem, restando-lhes o crescente avanço do poder psiquiátrico como regra de correção e de padrão de normalidade ${ }^{7}$ (VIANA, 2014).

Em Sergipe, além das práticas de inspeção escolar higiênicas, importantes dispositivos de identificação da anormalidade e desvios na infância foram instituídos no período do Estado Novo: o S.A.P.S. (Serviço de Assistência aos Psicopatas de Sergipe) e o Gabinete de Biologia Criminal.

A inauguração do S.A.P.S., sob direção do Dr. Garcia Moreno, ocorreu no $2^{\circ}$ Congresso de Neurologia, Psiquiatria e Higiene Mental do Nordeste Brasileiro, realizada no Instituto Histórico e Geográfico de Sergipe em 1940.

Segundo Arruda (1991), as sessões apresentadas versaram sobre trabalhos desenvolvidos no campo da Neurologia, da Psiquiatria, da Sociologia, de tratamentos utilizados (como a convulsoterapia) e temas de higiene mental. Nesse tema, destacaram-se os conhecimentos produzidos na aproximação com a educação, pois a autora destaca a leitura do Relatório oficial pela "Senhorinha" Anita Paes Barreto ${ }^{8}$, que tinha como título "Organização de classes homogêneas nas escolas primárias" (ARRUDA, 1991, p. 12); e a conferência

\footnotetext{
${ }^{7}$ Desde Itard, em 1800, aparece a defesa da educação como central no tratamento daqueles que não possuem o desenvolvimento de suas faculdades mentais.

8 Anita Paes Barreto foi uma professora pernambucana que trabalhou junto ao Dr. Ulisses Pernambucano na divulgação de estudos sobre a psicologia aplicada; coordenou várias pesquisas tendo como tema a Revisão Pernambucana do Teste de Binet, Simon, Terman, cujos resultados foram publicados principalmente em Neurobiologia, Jornal de Medicina de Pernambuco e Arquivos da Assistência a Psicopatas de Pernambuco. Dentre outras funções, foi diretora da escola de anormais Aires Gama de 1942-1957 (ANITA PAES BARRETO, 2000, grifo do original).
} 
realizada pelo Professor Acrísio Cruz intitulada "A personalidade infantil e a escola" e outra proferida pelo Dr. Leite Neto, intitulada "Repressão e Profilaxia do Crime".

Os conteúdos presentes nos temas do Congresso evidenciam a aproximação da higiene mental, da psiquiatria e o ambiente escolar. Aproximação a nível de saberes apropriados, uma vez que o uso das práticas psicométricas da inteligência e da personalidade foram identificados tanto nos hospitais psiquiátricos (pertencentes ao S.A.P.S.) como nas escolas estaduais primárias (na formação das classes especiais na década de 1975).

O S.A.P.S. foi organizado inicialmente por meio de três dispositivos: O Hospital Colônia Eronides de Carvalho ${ }^{9}$, o Consultório Neuro-Psiquiátrico e Escritório de Higiene Mental e o Laboratório de Análise Clínicas do S.A.P.S; foi regulamentado por meio do Decreto no 63 de 10/12/1940, publicado no Diário Oficial de Sergipe de 11/12/1940:

Artigo único: O Serviço de Assistência a Psicopatas de Sergipe reger-se-à pelo Regulamento que com este baixa, revogadas as disposições em contrário.

Regulamento do serviço de Assistência a Psicopatas de Sergipe Cap. I Assistência, fins, manutenção e movimento financeiro.

Art.1. O Serviço de Assistência a Psicopatas de Sergipe está diretamente subordinado à Secretaria de Justiça e Negócios do Interior.

Art. 2. O Serviço de Assistência a Psicopatas destina-se:

1) a assistir os psicopatas ou não;

2) a estudar, para fins periciais, os criminosos e os acusados suspeitos de alienação mental.

3) a fazer estudo etiológico de psicopatas, conhecer pela indagação ampla em todos os sentidos, a mentalidade do sergipano. Os motivos de seus desajustes psíquicos, afim de ditar conselhos de profilaxia e higiene mentais (SERGIPE, 1940, apud ARRUDA, 1991).

A regulamentação evidencia seu caráter tanto de tratamento dos doentes mentais como de identificação e de prevenção dos desvios. No campo preventivo, estrategicamente há a figura de dois monitores, que pertenciam ao Escritório de Higiene Mental, cuja função segundo o Dr. Garcia Moreno era:

o Monitor de Higiene Mental deve descobrir os anormais, retardados, predispostos e super-normais, nos meios escolares, a fim de dar a necessária orientação a cada caso; surpreender então os trabalhadores de indústria, as personalidades psicopáticas, para encaminhá-las aos serviços de assistência, proteger e vigiar os egressos do manicômio, criar-lhes hábitos de higiene psíquica, e estudando a capacidade de utilização social, acompanhar nos meios familiares os seus conselhos e a sua vigilância, os ex-internados do Hospital-Colônia, orientando os seus hábitos de vida, e sua vocação profissional ou o seu tratamento. Enfim exercer na sociedade uma ação fecunda de higiene mental, estudando as causas gerais e locais dos Psicopatas e os meios de combatê-los, difundindo conselhos verbais nos vários meios que frequentarem (ARRUDA, 1991).

\footnotetext{
${ }^{9}$ Outros dois hospitais substituíram o Hospital Colônia, em 1951 o Hospital Clínica Adauto Botelho e em 1979 o Hospital Garcia Moreno,
} 
Ainda que a função dos monitores de higiene mental devesse ir além do acompanhamento e vigilância dos egressos do manicômio, esta foi a única função encontrada para os mesmos nos registros disponíveis do S.A.P.S. Não foram encontrados relatórios sobre outras ações, tão pouco aproximações destes com as escolas (SERGIPE, 2016).

Outro dispositivo encontrado na literatura foi o Gabinete de Biologia Criminal que funcionava anexo à Penitenciária Modelo e também teve destaque sob a direção do Dr. Garcia Moreno na década de 1940 (FERREIRA, 2004).

Ambos os dispositivos, o S.A.P.S. e o Gabinete de Biologia Criminal, tinham por função identificar os traços de anormalidade na população sergipana e também na infância como é revelado na historiografia sergipana (COSTA; MENDES; FARIAS, 2014; COSTA; MENDES, 2015; MENDES, 2014).

Os caminhos institucionais sergipanos na captura da anormalidade na infância caminharam em consonância com dispositivos instituídos em outros locais do Brasil. Os discursos científicos que justificaram e fundamentaram a criação dos dispositivos, como o S.A.P.S. e o Gabinete de Biologia Criminal, defendiam o problema da anormalidade no indivíduo, ou seja na própria criança e no que ela trazia de herança familiar, ainda que se tivesse iniciado um discurso voltado para o ambiente e o contexto que esta criança crescia, não era isso que fundamentalmente ocupava as páginas dos relatórios que objetivaram a infância nestes dispositivos.

Este saber poder fundamentado em teorias sobre a hereditariedade e anormalidade, sobretudo advindas da Europa, produziu discursos e práticas voltadas à infância em diversas instituições, como as ligadas ao poder psiquiátrico, caracterizando o S.A.P.S. e o Gabinete de Biologia Criminal, como dispositivos de poder em prol da "caçada dos anormais" em terras sergipanas.

\section{Considerações finais}

A união dos saberes biomédicos aos educacionais resultou na emergência do biopoder na Educação, produzindo dispositivos normalizadores da infância identificados nos discursos, práticas e instituições no Brasil e, como em outros estados, em Sergipe.

A microfísica do poder representada pela união dos saberes biomédicos à educação produziu práticas, discursos, representações e a institucionalização da infância em sua normalidade e anormalidade, atingindo os corpos, os comportamentos, os hábitos, costumes das crianças e suas famílias, além dos professores. Da medicina higienista à psicologia, a apropriação destes saberes foi determinante no processo de cientificização da pedagogia e produção de dispositivos normalizadores, configurando instituições especializadas e estratégias deste biopoder como os testes, exames e avaliações em larga escala da infância.

A emergência das reformas escolares por meio dos pressupostos escolanovistas reforçam isso e caracterizam seu auge. O discurso produzido por Lourenço Filho, na difusão dessa nova compreensão de educação e do processo de ensino, estava carregado de fundamentação advinda da psicologia experimental, que tendo como expoente, as produções francesas, sobretudo de Alfred Binet e seus colaboradores, trouxe em seu bojo princípios disciplinares higienistas de caráter eugênico e que de certa forma, elegeu aqueles que teriam acesso ou não ao espaço escolar por meio da psicometria e da representação apropriada da higiene mental dos desvios da normalidade da infância. Configurou-se um saber poder que serviu a uma elite que dirigia a democratização do ensino brasileiro e precisava dar conta do montante de alunos advindos de culturas e classes sociais populares e que não respondiam ao projeto social e econômico do Brasil.

Para tanto, dispositivos normalizadores e de governo da infância foram criados no contexto nacional e em Sergipe nas primeiras décadas do século XX. Em consonância com a 
política e as práticas que vinham sendo desenvolvidas no Brasil, as crianças e adolescentes sergipanas também tiveram sua vida esquadrinhada e assujeitada por dispositivos normalizadores, destacados aqui o Serviço de Assistência aos Psicopatas e o Gabinete de Biologia Criminal que determinaram tanto as possibilidades de educação como de convívio social de muitos sergipanos.

\section{Referências}

ANITA Paes Barreto. Psicologia: ciência e profissão. v.20, n.3. Brasília. set. 2000. Disponível em: http://pepsic.bvsalud.org/scielo.php?script=sci_arttext\&pid=S141498932000000300009\&lng=pt\&nrm=iso\&tlng=pt. Acesso em: 30 mai 2020. https://doi.org/10.1590/S1414-98932000000300009

ARRUDA, Márcia. Os primórdios da psiquiatria em Sergipe. Aracaju: Fundação Augusto Franco, 1991.

BRASIL. Decreto no 24.559, de 3 de Julho de 1934._Dispõe sôbre a profilaxia mental, a assistência e proteção á pessôa e aos bens dos psicopatas, a fiscalização dos serviços psiquiátricos e dá outras providências. Disponível em: < http://www2.camara.leg.br/legin/fed/ decret/1930-1939/decreto-24559-3-julho-1934-515889-publicacaooriginal-1-pe.html>.

Acesso em: 07 jan. 2017.

CARVALHO, Marta Maria Chagas de. Pedagogia da Escola Nova, produção da natureza infantil e controle doutrinário da escola. In: FREITAS, Marcos Cesar de; KUHLMANN JÚNIOR. (org.); Moysés. Os intelectuais na história da infância. São Paulo: Cortez, 2002. p.373- 408.

CARVAlHO, Marta Maria Chagas de. Quando a história da educação é a história da disciplina e da higienização das pessoas. In: FREITAS, Marcos Cezar de (org). História social da infância no Brasil. $6^{a}$ ed. São Paulo: Cortez, 2006. p.291-310.

CARVALHO, Marta Maria Chagas de. Reformas da instrução pública. In: LOPES, Eliane Marta Teixeira; FARIA FILHO, Luciano Mendes de; VEIGA, Cynthia Greive (orgs.). 500 anos de educação no Brasil. 4. ed. Belo Horizonte: Autêntica, 2010. p. 225-252.

CORRÊA, Mariza. A cidade de menores: uma utopia dos anos 30. In: FREITAS, Marcos C. (org.). História social da infância no Brasil. 8. ed. São Paulo: Cortez, 2006. p. 81-99.

COSTA, Katia Regina Lopes; MENDES, Alessandro Araujo; FREITAS, Anamaria Gonçalves Bueno de. O Gabinete de Biologia Criminal e o Serviço de Atendimento aos Psicopatas em Sergipe: Aproximações entre a História da Educação e a Medicina. SAECULUM- Revista de História, n.31, João Pessoa, jul/dez, 2014. p.141-156.

COSTA, Katia Regina Lopes; MENDES, Alessandro Araújo. Os menores "anormais", o Gabinete de Biologia Criminal e o Serviço de Atendimento aos Psicopatas em Sergipe (1920 a 1970). In: CONGRESSO BRASILEIRO DE HISTÓRIA DA EDUCAÇÃO, VIII. Anais.... Universidade Estadual de Maringá. 29 de Junho a 02 julho de 2015.

CUNHA, Marcus Vinicius da. A escola contra a família. LOPES, Eliane Marta Teixeira; FARIA FILHO, Luciano Mendes de; VEIGA, Cynthia Greive (orgs.). 500 anos de Educação no Brasil. 4. ed. Belo Horizonte: Autêntica, 2010. p. 447-468. 
FERREIRA, Otília Tatiana de Cácia da Conceição. Entre o discurso médico e o jurídico: Garcia Moreno e as primeiras interferências da medicina legal em Sergipe (década de 1940). Monografia (Licenciatura em História). 2004. 48 f. São Cristóvão: Universidade Federal de Sergipe, 2004.

FERREIRA, Carla Mercês da Rocha Jatobá. Às Sombras das Escalas: um estudo sobre a concepção de anormalidade em Alfred Binet. $1^{a}$ ed. Belo Horizonte, MG: Fino Traço, 2016. 168 p.

FONTOURA, Afro do Amaral. Fundamentos de Educação (Uma Introdução Geral à Educação Renovada e À Escola Viva): Princípios Psicológicos e Sociais, Elementos de Didática, Administração Escolar. 7ª edição. Rio de Janeiro: Gráfica Editora Aurora, 1965

FOUCAULT, Michel. Microfísica do poder. Organização e tradução de Roberto Machado. 4. ed. Rio Janeiro: Graal, 1984. 472p.

FOUCAULT, Michel. A ordem do discurso. Aula inaugural no Collège de France, Pronunciada em 2 de dezembro de 1970. Tradução de Laura Fraga de Almeida Sampaio. 5. ed. São Paulo: Loyola, 1999. 79p.

FOUCAULT, Michel. Os anormais: curso no Collège de France (1974-1975). Tradução Eduardo Brandão. São Paulo: Martins Fontes, 2001. 479p.

FOUCAULT, Michel. O poder psiquiátrico: curso dado no Collège de France (1973-1974). Trad. Eduardo Brandão. São Paulo: Martins Fontes, 2006. 511p.

FREITAS, Anamaria Gonçalves Bueno de. A escola nova em Sergipe na primeira metade do século XX. In: CONGRESSO BRASILEIRO DE HISTÓRIA DA EDUCAÇÃO. VI Anais Eletrônicos... Vitória. 2011. Disponível em: http://www.sbhe.org.br/novo/congressos/cbhe6/ anais_vi_cbhe/conteudo/res/trab_932.ht. Acessado em: 20 jun. 2016.

GINZBURG, Carlo. Mitos, emblemas, sinais: morfologia e história. Tradução: Federico Carotti. $2^{a}$ edição. $4^{\mathrm{a}}$ reimpressão. São Paulo: Companhia das Letras, 2011.

GINZBURG, Carlo. O queijo e os vermes - o cotidiano e as idéias de um moleiro perseguido pela Inquisição. Tradução Maria Betânia Amoroso; tradução dos poemas José Paulo Paes. São Paulo, Companhia das Letras, 2006. 255p. 2 reimpressão.

GONDRA, José G. "Modificar com brandura e prevenir com cautela": Racionalidade médica e higienização da infância. In: FREITAS, Marcos Cesar de; KUHLMANN JÚNIOR, Moysés (orgs.). Os intelectuais na história da infância. São Paulo: Cortez, 2002. p. 289-318.

GONDRA. José. Medicina, higiene e educação escolar. In: LOPES, Eliane Marta Teixeira; FARIA FILHO, Luciano Mendes de; VEIGA, Cynthia Greive (orgs.) 500 anos da educação no Brasil. 4. ed. Belo Horizonte: Autêntica, 2010. p. 519-550.

GONDRA, José G. Estropiados, tarados, imbecis, loucos, criminosos e incapazes: o processo de normalização da casa e da escola em questão. In: RESENDE, Haroldo de (org.). Michel Foucault: o Governo da infância. Belo Horizonte: Autêntica Editora, 2015 (Coleção Estudos Foucaultianos) p.141-164. 
JANNUZZI, Gilberta, S. de M. A educação do deficiente no Brasil: dos primórdios ao início do século XXI. 2. ed. Campinas, SP: Autores Associados, 2006, 243p.

LOBO, Lilia Ferreira. Os infames da história: pobres, escravos e deficientes no Brasil. 2 ed. Rio de Janeiro: Lamparina, 2015. 426p.

LOPES, Eliane Marta Teixeira. A psicanálise aplicada às crianças do Brasil: Artur Ramos e a "criança problema". In: FREITAS, Marcos Cesar de; KUHLMANN JÚNIOR. Moysés (orgs.). Os intelectuais na história da infância. São Paulo: Cortez, 2002. p.319- 343.

LOURENÇO FILHO, Manuel Bergström, Introdução ao estudo da escola nova: bases, sistemas e diretrizes da pedagogia contemporânea. 12. ed. São Paulo: Melhoramentos; Rio de Janeiro: Fundação Nacional de Material Escolar, 1978. 271p.

MACHADO, Roberto; LOUREURO, Angela; LUZ, Rogerio; MURICY, Katia. Danação da norma: a medicina social e constituição da psiquiatria no Brasil. Rio de Janeiro: Graal, 1978. 559p.

MENDES, Alessandro Araújo. O menor abandonado e delinquente em Sergipe: da instrução ao cárcere (1942-1974). 2014. 208 f. Dissertação (Mestrado em Educação). São Cristóvão: Universidade Federal de Sergipe, 2014.

MINATEL, Martha Morais. Institucionalização e Educação do menor anormal em Sergipe (1940-1979). 2018. 230f. Tese (Doutorado em Educação). Universidade Federal de Sergipe, São Cristóvão, 2018.

NASCIMENTO, Jorge Carvalho do. As viagens pedagógicas. São Paulo Difundindo a Pedagogia Moderna e a Escola Nova no Brasil. Cadernos CERU, série 2, n.14, 2003.

NUNES, Clarice. (Des)encantos da modernidade pedagógica. LOPES, Eliane Marta Teixeira; FARIA FILHO, Luciano Mendes de; VEIGA, Cynthia Greive (orgs.). 500 anos de Educação no Brasil. $4^{\mathrm{a}}$ ed. Belo Horizonte: Autêntica, 2010. p.371- 398.

RESENDE, Haroldo de. A infância sob o olhar da Pedagogia: traços da escolarização na Modernidade. In: RESENDE, Haroldo de (org.). Michel Foucault: o Governo da infância. Belo Horizonte: Autêntica, 2015 (Coleção Estudos Foucaultianos). P. 127-140

SERGIPE. Arquivo Central da Saúde, Caixas contendo documentos dos internos nos hospitais Adauto Botelho e Garcia Moreno (1940-1979). Aracaju, 2016.

SILVA, Maria Neide Sobral da. Ecos de uma viagem: Rocha Lima e a Escola Nova em Sergipe. In: CONGRESSO BRASILEIRO DE HISTÓRIA DA EDUCAÇÃO. II Anais Eletrônicos.... Natal, 2002. Disponível em: <http://sbhe.org.br/novo/congressos/cbhe2/pdfs/Tema4/0437.pdf >. Acessado em 20 jun. 2016

VALENÇA, Cristina de Almeida. Civilizar, regenerar e higienizar: a difusão dos ideais da Pedagogia Moderna por Helvécio de Andrade (1911-1935). 2006. 234 f. Dissertação (Mestrado em Educação) São Cristóvão: Universidade Federal de Sergipe, 2006.

VIANA, Bruna da Silveira. "É um completo idiota, não faz nada.": discussões acerca dos diagnósticos de crianças e jovens no Hospital Colônia Sant'Ana (1942-1944). In: 
SEMINÁRIO NACIONAL DE HISTÓRIA DA CIÊNCIA E DA TECNOLOGIA- $14^{\circ}$ SNHCT. Anais eletrônicos... Belo Horizonte, Campus Pampulha da Universidade Federal de Minas Gerais- UFMG08 a 11 de outubro de 2014. ISBN: 978-85-62707-62-9

VEIGA, Cynthia Greive. Infância e modernidade: ações, saberes e sujeitos. In FARIA FILHO, Luciano Mendes (org). A infância e sua educação - materiais, práticas e representações (Portugal e Brasil). Belo Horizonte: Autêntica, 2004. p.35-82

VIDAL. Diana Gonçalves. Escola Nova e Processo Educativo. In: LOPES, Eliane Marta Teixeira; FARIA FILHO, Luciano Mendes de; VEIGA, Cynthia Greive (orgs.). 500 anos de educação no Brasil. 4. ed. Belo Horizonte: Autêntica, 2010. p. 497-518. 